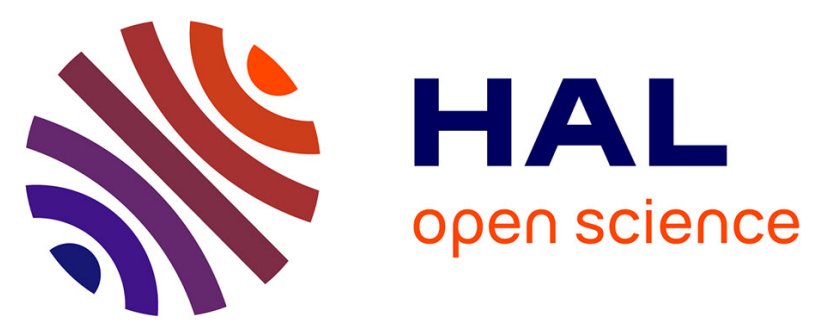

\title{
SPART: A versatile and standardized data exchange format for species partition information
}

Aurélien Miralles, Jacques Ducasse, Sophie Brouillet, Tomas Flouri, Tomochika Fujisawa, Paschalia Kapli, L. Lacey Lacey Knowles, Sangeeta

Kumari, Alexandros Stamatakis, Jeet Sukumaran, et al.

\section{To cite this version:}

Aurélien Miralles, Jacques Ducasse, Sophie Brouillet, Tomas Flouri, Tomochika Fujisawa, et al.. SPART: A versatile and standardized data exchange format for species partition information. Molecular Ecology Resources, 2021, 22, 10.1111/1755-0998.13470 . hal-03374290

\section{HAL Id: hal-03374290 \\ https://hal.sorbonne-universite.fr/hal-03374290}

Submitted on 12 Oct 2021

HAL is a multi-disciplinary open access archive for the deposit and dissemination of scientific research documents, whether they are published or not. The documents may come from teaching and research institutions in France or abroad, or from public or private research centers.
L'archive ouverte pluridisciplinaire HAL, est destinée au dépôt et à la diffusion de documents scientifiques de niveau recherche, publiés ou non, émanant des établissements d'enseignement et de recherche français ou étrangers, des laboratoires publics ou privés. 
6 Aurélien Miralles ${ }^{1 *}$, Jacques Ducasse $^{2}$, Sophie Brouillet ${ }^{1}$, Tomas Flouri $^{3}$, Tomochika 7 Fujisawa $^{4}$, Paschalia Kapli ${ }^{3}$, L. Lacey Knowles ${ }^{5}$, Sangeeta Kumari ${ }^{6}$, Alexandros 8 Stamatakis $^{7,8}$, Jeet Sukumaran ${ }^{9}$, Sarah Lutteropp $^{7}$, Miguel Vences ${ }^{6 *}$, Nicolas Puillandre ${ }^{1 *}$

\section{9}

10 Institut de Systématique, Évolution, Biodiversité (ISYEB), Muséum national d'Histoire naturelle, CNRS, 11 Sorbonne Université, EPHE, Université des Antilles 57 rue Cuvier, CP 50, 75005 Paris, France

$12{ }^{2} 49$ rue Eugène Carrière, 75018 Paris, France

$13{ }^{3}$ Centre for Life's Origins and Evolution, Department of Genetics, Evolution and Environment, University

14 College London, London WC1E 6BT, UK

$15{ }^{4}$ Center for Data Science and Education and Research, Shiga University, 1-1-1 Banba, Hikone, 522-8522, Shiga,

16 Japan

$17 \quad{ }^{5}$ Department of Ecology and Evolution, University of Michigan, Ann Arbor, MI 48109, USA

$18{ }^{6}$ Braunschweig University of Technology, Zoological Institute, Mendelssohnstraße 4, 38106 Braunschweig,

19 Germany

$20{ }^{7}$ Computational Molecular Evolution Group, Heidelberg Institute for Theoretical Studies, Schloss-

21 Wolfsbrunnenweg 35, 69118 Heidelberg Germany

$22{ }^{8}$ Institute for Theoretical Informatics, Karlsruhe Institute of Technology, Am Fasanengarten 5, 76131 Karlsruhe,

23 Germany

$24{ }^{9}$ Biology Department, LS 262, San Diego State University, 5500 Campanile Drive, San Diego, CA 92182-4614, 25 USA

26

$27 *$ Corresponding authors

28 Contact: miralles.skink@gmail.com, m.vences@tu-braunschweig.de, nicolaspuillandre@gmail.com

29

30 Short running title: SPART, a standardized format for species partition 


\section{Abstract}

32

33 A wide range of data types can be used to delimit species and various computer-based tools

34 dedicated to this task are now available. Although these formalized approaches have

35 significantly contributed to increase the objectivity of SD under different assumptions, they

36 are not routinely used by alpha-taxonomists. One obvious shortcoming is the lack of

37 interoperability among the various independently developed SD programs. Given the frequent

38 incongruences between species partitions inferred by different SD approaches, researchers

39 applying these methods often seek to compare these alternative species partitions to evaluate

40 the robustness of the species boundaries. This procedure is excessively time consuming at

41 present, and the lack of a standard format for species partitions is a major obstacle. Here we

42 propose a standardized format, SPART, to enable compatibility between different SD tools

43 exporting or importing partitions. This format reports the partitions and describes, for each of

44 them, the assignment of individuals to the "inferred species". The syntax also allows to

45 optionally report support values, as well as original trees and the full command lines used in

46 the respective SD analyses. Two variants of this format are proposed, overall using the same

47 terminology but presenting the data either optimized for human readability (matricial SPART)

48 or in a format in which each partition forms a separate block (SPART.XML). ABGD,

49 DELINEATE, GMYC, PTP and TR2 have already been adapted to output SPART files and a

50 new version of LIMES has been developed to import, export, merge and split them.

52 Key words. Species delimitation programs; SPART; Species partition format; Integrative

53 taxonomy; LIMES v2.0 


\section{Introduction}

56

57 Species delimitation (SD) is a burgeoning, fully fledged research field in systematic biology

58 (Sites \& Marshall 2003; Camargo \& Sites 2013; Flot 2015, Ducasse et al. 2020). SD benefits

59 from the interpretation of species as independent evolutionary lineages (De Queiroz 1998,

60 2007) that can be distinguished from each other using a variety of operational SD criteria

61 (Samadi \& Barberousse 2006). In integrative taxonomy (Dayrat 2005; Padial et al. 2010),

62 various lines of evidence and a wide range of data types can be used in formalised analytical

63 workflows to propose species hypotheses, from DNA barcodes to phylogenomic data, discrete

64 morphological characters, morphometric measurements, ecological traits, geographic

65 occurrence, bioacoustic signals, metabolomic profiles, and others (Miralles et al. 2020).

66

67

68

69

70

71

72

73

74

75

76

77

78

If many, and among them the earliest, formalised SD procedures are mostly carried out manually, e.g. by comparing trees with the geographic occurrence of individuals, calculating correlations between geographic and genetic distances, assessing steepness of hybrid zones, or seeking for correlation between genetic distance and morphological characters (Good \& Wake 1992, Wiens \& Penkrot 2002, Vieites et al. 2009, Flot et al. 2010, Weisrock et al. 2010, Puillandre et al. 2012a, Miralles \& Vences 2013, Derkarabetian \& Hedin 2014, Dufresnes et al. 2015), a substantial number of computer-based tools has been developed to delimit species, often based on statistical criteria. These programs can analyse large datasets, with a strong focus on the use of sequence data (Table 1). These methods have significantly contributed to increase the objectivity, repeatability, and speed of species delimitation inferences under different mathematical models and assumptions (e.g. Multispecies coalescent model, DNA barcode gap, haplotype fields of recombination, cf. de Queiroz 1998, 
79 2007, Knowles \& Carstens 2007, Yang \& Rannala 2010, Carstens et al. 2013, Leavitt et al.

80 2015, Rannala 2015).

81

82 Although the number and importance of SD tools is likely to sharply increase in the

83 immediate future, they are not yet routinely used in the majority of alpha-taxonomic studies

84 that result in the naming of over 15,000 new species of organisms every year (Miralles et al.

85 2020). One obvious shortcoming is the lack of interoperability among the various

86 independently developed SD programs, and the lack of comprehensive software suites that

87 offer various user-friendly features, such as those for data visualization and comparison of

88 results across methods. For instance, incongruent species partitions resulting from different

89 SD approaches applied to a given dataset are common. They can even be significant, if not

90 striking in some cases (such as excessive splitting or lumping leading to highly different

91 number of species delimited; Carstens et al. 2013, Miralles \& Vences 2013, Dellicour \& Flot

92 2015, Kapli et al. 2016, Postaire et al. 2016, Renner et al. 2017 for empirical cases; and

93 Sukumaran \& Knowles 2017, Chan et al 2020, Luo et al. 2018, Mason et al. 2020 and Zhang

94 et al. 2011 for more methodological studies on SD limitations). Integrative taxonomists will

95 seek to compare these alternative species partitions across SD approaches (but see Rannala

96 2015), and eventually estimate their robustness by integrating other data sources

97 (morphological variation, geographic distribution, etc), in order to make an informed choice-

98 a procedure that is excessively time consuming at present, given the lack of a standard format

99 for species partitions. 
101 The main output of species delimitation, and therefore of any SD program, is a species

102 partition. The term "partition" here follows the set theory concept: the organization of a set of

103 elements into mutually-exclusive and jointly-comprehensive subsets, not including the empty

104 subset (Hrbacek \& Jech 1999). In an SD application, the elements are individuals (i.e.

105 samples or specimens), and a specific species delimitation hypothesis is a particular

106 assignment (i.e. a partition) of these individuals to subsets, where each subset corresponds to

107 a distinct inferred species. Categories resulting from an SD analysis have been referred to by

108 various terms, such as primary species hypothesis, operational taxonomic unit (OTUs),

109 barcode index number (BINs; Ratnasingham \& Hebert 2013), or even cluster (without any

110 particular status (Fig. 1)), but all of them match the aforementioned definition of a subset.

111 Furthermore, while some tools produce de novo species partitions (i.e. directly aggregating

112 individuals into species hypotheses; exploratory methods), others statistically compare

113 competing species hypotheses that have been defined a priori (hypothesis-testing methods),

114 and these programs require a species partition as input. SD methods may also assign scores,

115 either to the entire inferred partition (e.g., ASAP-score in the program ASAP; Puillandre et al.

116 2021), to the distinctiveness of each subset from the others (e.g., posterior probabilities in the

117 programs BPP and bPTP; Yang \& Rannala 2010; Zhang et al. 2013), or to the presence of

118 each individual in a given subset (e.g., probability of placement in calculation of BINs,

119 Ratnasingham \& Hebert 2013).

121 A standardized Species PARTition format (SPART)

123 Typically, each SD program exports the resulting species partitions in its own idiosyncratic

124 format. Some, for instance, provide a table of assignments of individual specimens to the 
125 subsets (e.g. GMYC) while others, conversely, list the different subsets with the included

126 individuals (e.g. ABGD, PTP), whereas again others graphically report subsets on a tree

127 topology (e.g. GMYC). These different formats may or may not include complementary data

128 (e.g., scores, topologies, metadata, number of species delimited, etc.), and are not designed to

129 be parsed by other tools for downstream analyses. Their manual conversion into a versatile

130 and easily reusable plain text species partition (e.g., CSV) is not always straightforward. It

131 can be particularly error prone and time consuming with large datasets, as species

132 delimitations on several hundreds, or even thousands, of specimens are becoming common

133 practice in molecular taxonomy (e.g., Ahrens et al. 2016, Renner et al 2017, Garcià-Melo et

134 al. 2019, Hoffmann et al. 2019, Solihah et al. 2020, Christodoulou et al. 2020).

136 We here propose a standardized species partition format, SPART, to enable compatibility

137 between different tools producing (export) or using (import) species partitions. Our format

138 facilitates:

139 (1) statistical comparison of different alternative species partitions such as their overall

140 congruence, similarity or resolving power, identification of the subsets that are congruently

141 delimited (currently implemented in the program LIMES v2.0; Ducasse et al. 2020);

142 (2) assessment of multiple competing SD hypotheses, including those used as input in e.g.

143 DELINEATE and BPP to evaluate them (Sukumaran et al. 2020, Yang \& Rannala 2010);

144 (3) visualization and comparison of species partitions (e.g., DNA-based species partitions

145 compared with manually-edited species partitions obtained from alternative methods and data 
146 such as Principal Component Analysis of morphometry, haplotype networks, geographic

147 distribution, habitat type, external phenetic similarity, or simply, current taxonomy);

148 (4) extraction, from original data files, of specific data for each subset under different

149 species partition assumptions (e.g. lists of molecular and morphological diagnostic character

150 states, descriptive statistics characterizing each of the inferred species, or ecological or

151 distributional traits); and

152 (5) potential taxonomic reassignment of specimens in databases.

154 More generally, the SPART format is designed to be versatile and fully integrative in the

155 sense that it can include any species partition descriptors, independently of the method or

156 data-type used to generate the species partition (Fig. 2). SPART does not convey any

157 interpretation on the quality of the species partition, nor on the pros and cons of the methods

158 used to define them, but is simply a common format that seeks at homogenising the way

159 species partitions are recorded. It can therefore be implemented in any method used to

160 generate one or several species partitions as output. Likewise, any method using (analysing,

161 comparing, automatically reassigning or graphically representing) multiple subsets of

162 specimens might benefit from being able to import SPART files as input data.

163

164 Matricial and serial implementation of the SPART format 
166 SPART files include information on one or multiple species partitions for a given set of

167 elements (i.e. individuals) and use standardized terminology to denote the number of species

168 partitions included in the file ("N_spartitions") and for each partition, the number of

169 individuals ("N_individuals"), number of subsets ("N_subsets"), and the assignment of

170 individuals to subsets (“Assignment”) (Supporting information 1). The syntax also allows to

171 optionally include support values for species partitions, subsets, and the assignment of

172 individuals to subsets, as well as original trees and the full command line used in the

173 respective SD analyses, the program version number as well as comments and species

174 partition comparison indices as calculated with LIMES 2.0, a new version of LIMES

175 (Ducasse et al. 2020) recently published.

To account for the diversity of possible future applications, we propose two variants of

177 the SPART format (for details see Supporting information 1). Both of these use largely the

178 same terminology but represent the data differently:

179 The first SPART variant is optimized for human readability and its syntax has been

180 designed to be compatible with Nexus (a widely used data format in phylogenetic inference

181 software: Maddison et al. 1997). This allows to include SPART specifications as blocks in

182 Nexus files if required by future applications. If information from multiple partitions is

183 included, then it is combined into a single block, presenting the respective assignments and

184 assignment scores per individual from different species partitions concatenated on a single

185 line, separated by separator symbols. This enables easy manual transformation into a

186 spreadsheet format if required. Due to the presentation of information from multiple partitions

187 in one block as a concatenated matrix, we denote this variant as matricial SPART format, or

188 simply SPART. 
The second SPART variant is optimized for machine readability, and relies on XML

190 (eXtensible Markup Language), a lightweight data-interchange format that can be easily

191 parsed and written by software tools, while it can still be read and written by humans as well.

192 When information from multiple partitions is included, each partition forms a separate block

193 containing information on the number of subsets, individual assignments and assignment

194 scores. We therefore denote this variant as SPART.XML format.

196 Tools already implementing SPART and future perspectives

197

198 The proposed format is already implemented in several widely-used SD programs. Both the

matricial SPART and SPART.XML output files are already generated by GUI-driven standalone versions (https://github.com/iTaxoTools) of ABGD, ASAP, GMYC, PTP, mPTP, TR2 and DELINEATE (Vences et al. submitted), by the native Python version of TR2, and in the web versions of ABGD and ASAP; and in progress for the Python versions of GMYC and PTP. Furthermore, the species partition comparison tool LIMES v2.0 has been expanded to import, export and convert SPART files, in particular to (1) compare, by calculating indices (e.g., Ctax, Ratx, Match Ratio, cf. Ducasse et al. 2020) for species partitions from SPART files (including each one or several species partitions); (2) merge species partitions included in different SPART files into one SPART file, (3) import species partition(s) table(s) from spreadsheet editors such as Microsoft EXCEL and save it (them) into a single SPART file. A new software tool named SPARTMAPPER has also been developed; it takes SPART files as input along with a tab-delimited series of geographical coordinates linked to specimen names, plots the distribution of alternative delimited species on a map, and exports a. $\mathrm{kml}$ file to visualize this information in Google Earth. 
214 manuscript, and the web based ABGD and ASAP are already freely available since February 2021

215 (https://bioinfo.mnhn.fr/abi/public/abgd/abgdweb.html, https://bioinfo.mnhn.fr/abi/public/asap/);

216 for review, various preliminary Windows executables are available under this link:

217 https://hidrive.ionos.com/share/ohaymwcgjd\#\$/Win\%20executables ]

218 In the context of future work, we envisage the development of visualization tools to

219 automatically illustrate information from species partitions along with support values and

220 phylogenetic hypotheses (Fig. 1). There is still a long way to go before programs will be able

221 to infer species based on combining evidence using different data sources such as genetics,

222 morphology, ecology, behaviour, geographic distribution, etc. However, eventually, reliable

223 computer-based, species delimitation procedures that mirror the procedures of integrative

224 taxonomy will be at the core of next generation taxonomy (Vences 2020). Our SPART data

225 exchange format would thus contribute to this next generation taxonomy, by simplifying

226 computational approaches to completing the inventory of life on Earth.

\section{Acknowledgments}

230

231 We are grateful to Susanne Renner who stimulated this work by leading the priority program

232 SPP 1991 "Taxon-Omics" of the Deutsche Forschungsgemeinschaft (DFG), specifically in the

233 context of a grant on taxonomic data integration and management (RE 603/29-1), and to

234 many members of the Taxon-Omics consortium and Guillaume Achaz (MNHN) for fruitful

235 discussion. MV and SK were supported by DFG grant VE247/20-1, NP by the European

236 Research Council (ERC) under the European Union's Horizon 2020 research and innovation

237 programme (grant agreement No. 865101), and AS and SL by the Klaus-Tschira foundation. 
bioRxiv preprint doi: https://doi.org/10.1101/2021.03.22.435428; this version posted March 22, 2021. The copyright holder for this preprint (which was not certified by peer review) is the author/funder, who has granted bioRxiv a license to display the preprint in perpetuity. It is made available under aCC-BY-NC 4.0 International license.

238

239

240

241 
244

245

246

247

248

249

250

251

252

253

254

255

256

257

258

259

260

261

262

263

264

265

266

267

268

269

270

271

272

273

274

275

276

277

278

279

280

281

282

283

284

285

286

\section{REFERENCES}

Ahrens, D., Fujisawa, T., Krammer, H. J., Eberle, J., Fabrizi, S., \& Vogler, A. P. (2016). Rarity and incomplete sampling in DNA-based species delimitation. Systematic Biology, 65, 478-494. doi:10.1093/sysbio/syw002

Camargo, A., \& Sites, J. Jr. (2013). Species delimitation: a decade after the renaissance. In: The Species Problem - Ongoing Issues (ed. I. Y. Pavlinov). IntechOpen.

Carstens, B. C., Pelletier, T. A., Reid, N. M., \& Satler, J. D. (2013). How to fail at species delimitation. Molecular Ecolology, 22, 4369-4383. doi:10.1111/mec.12413

Chan, K. O., Hutter, C. R., Wood, P. L. Jr,, Grismer, L. L., Das, I., \& Brown, R. M. (2020). Gene flow creates a mirage of cryptic species in a Southeast Asian spotted stream frog complex. Molecular Ecology, 29(20), 3970-3987. doi:10.1111/mec.15603

Christodoulou, M., O'Hara, T., Hugall, A. F., Khodami, S., Rodrigues, C. F., Hilario, A., Vink, A., \& Martinez Arbizu, P. (2020) Unexpected high abyssal ophiuroid diversity in polymetallic nodule fields of the northeast Pacific Ocean and implications for conservation, Biogeosciences, 17, 1845-1876. doi:10.5194/bg-17-1845-2020

Dayrat, B. (2005). Toward integrative taxonomy. Biological Journal of the Linnean Society, 85, 407-415. doi:10.1111/j.1095-8312.2005.00503.x

Dellicour, S., \& Flot J.-F. (2015). Delimiting species-poor data sets using single molecular markers: a study of barcode gaps, haplowebs and GMYC. Systematic Biology, 64, 900908. doi:10.1093/sysbio/syu 130

de Queiroz, K. (1998). The general lineage concept of species, species criteria, and the process of speciation. In: D.J. Howard \& S.H. Berlocher, S.H. (Eds.), Endless Forms: Species and Speciation. (pp. 57-75). New York: Oxford University Press.

de Queiroz, K. (2007). Species concepts and species delimitation, Systematic Biology, 56, 879-886. doi:10.1080/10635150701701083

Derkarabetian, S., \& Hedin, M. (2014). Integrative taxonomy and species delimitation in harvestmen: a revision of the western North American genus Sclerobunus (Opiliones: Laniatores: Travunioidea). PLoS One, 9, e104982. doi:10.1371/journal.pone.0104982

Ducasse, J., Ung, V., Lecointre, G., Miralles, A. (2020). LIMES : a tool for comparing species partition. Bioinformatics, 2282-2283. doi:10.1093/bioinformatics/btz911

Dufresnes, C., Brelsford, A., Crnobrnja-Isailović, J., Tzankov, N., Lymberakis, P., \& Perrin, N. (2015). Timeframe of speciation inferred from secondary contact zones in the European tree frog radiation (Hyla arborea group). BMC Evolutionary Biology 15, 1-8. doi: 10.1186/s12862-015-0385-2

Ence, D.D., \& Carstens, B.C. (2011). SpedeSTEM: A rapid and accurate method for species delimitation. Molecular Ecolology Resources, 11, 473-480. doi:10.1111/j.17550998.2010.02947.x

Flot, J.-F., Couloux, A., \& Tillier, S. (2010). Haplowebs as a graphical tool for delimiting species: a revival of Doyle's "field for recombination" approach and its application to the coral genus Pocillopora in Clipperton. BMC Evolutionary Biology, 10, 372. doi:10.1186/1471-2148-10-372 
Flot, J.-F. (2015). Species delimitation's coming of age, Systematic Biology, 64, 897-899.

Fontaneto, D., Herniou, E., Boschetti, C., Caprioli, M., Melone, G., Ricci, C., \& Barraclough, T.G. (2007). Independently evolving species in asexual bdelloid rotifers. PLoS Biology, 5, e87. doi:10.1371/journal.pbio.0050087

Fujisawa, T., Aswad, A., Barraclough, T. G. (2016). A rapid and scalable method for multilocus species delimitation using Bayesian model comparison and rooted triplets. Systematic Biology, 65(5), 759-771. doi:10.1093/sysbio/syw028

García-Melo, J. E., Oliveira, C., Da Costa Silva, G. J., Ochoa-Orrego, L. E., Garcia Pereira, L. H., Maldonado-Ocampo, J. A. (2019). Species delimitation of Neotropical characins (Stevardiinae): Implications for taxonomy of complex groups. PLoS ONE 14(6), e0216786. doi:10.1371/journal.pone.0216786

Good, D. A., \& Wake, D. B. (1992). Geographic variation and speciation in the torrent salamanders of the genus Rhyacotriton (Caudata: Rhyacotritonidae). University of California Publications in Zoology, 126, 1-91.

Hofmann, E. P., Nicholson, K. E., Luque-Montes, I. R., Köhler, G., Cerrato-Mendoza, C. A., Medina-Flores, M., Wilson, L. D., \& Townsend, J. H. (2019). Cryptic diversity, but to what extent? Discordance between single-locus species delimitation methods within mainland anoles (Squamata: Dactyloidae) of Northern Central America. Frontiers in Genetics. 10,11. doi:10.3389/fgene.2019.00011

Hrbacek, K. \& Jech, T. (1999). Introduction to set theory, third edition, revised and expanded. Monographs and Textbooks in pure and applied mathematics, vol. 220, Marcel Dekker Inc. Ney York, Basel.

Jones, G. (2017). Algorithmic improvements to species delimitation and phylogeny estimation under the multispecies coalescent. Journal of Mathematical Biology, 74, 447. doi:10.1007/s00285-016-1034-0

Jones, G., Aydin, Z., \& Oxelman, B. (2014). DISSECT: An assignment free Bayesian discovery method for species delimitation under the multispecies coalescent. Bioinformatics, 31, 991-998. doi:10.1093/bioinformatics/btu770

Kapli, P., Lutteropp, S., Zhang, J., Kobert, K., Pavlidis, P., Stamatakis, A., \& Flouri, T. (2016). Multi-rate Poisson Tree Processes for single-locus species delimitation under Maximum Likelihood and Markov Chain Monte Carlo. Bioinformatics, 33, 1630-1638. doi:10.1093/bioinformatics/btx025

Knowles, L. L., Carstens, B. C. (2007) Delimiting species without monophyletic gene trees. Systematic Biology, 56 (6), 887-895. doi :10.1080/10635150701701091

Leavitt, S. D., Moreau, C. S., \& Lumbsch, H. T. (2015). The dynamic discipline of species delimitation: Progress toward effectively recognizing species boundaries in natural populations. In Recent Advances in Lichenology (pp. 11-44). New Delhi: Springer. doi:10.1007/978-81-322-2235-4 2

Luo, A., Ling, C., Ho, S. Y. W., Zhu, C.-D. (2018). Comparison of methods for molecular species delimitation across a range of speciation scenarios. Systematic Biology, 67(5), 830846. doi:10.1093/sysbio/syy011

Maddison, D. R., Swofford, D. L., Maddison, W. P. (1997). NEXUS: An extensible file format for systematic information. Systematic Biology, 46, 590-621. doi:10.1093/sysbio/46.4.590

Mason, N. A., Fletcher, N. K., Gill, B. A., Funk, C., Zamudio, K. R. (2020). Coalescent-based species delimitation is sensitive to geographic sampling and isolation by distance. Systematics and Biodiversity, 18(3), 269-280. doi:10.1080/14772000.2020.1730475 
Masters, B. C., Fan, V., \& Ross, H. A. (2011). Species Delimitation - a Geneious plugin for the exploration of species boundaries. Molecular Ecology Resources, 11, 154-157. doi:10.1111/j.1755-0998.2010.02896.x

Miralles, A. \& Vences, M. (2013). New metrics for comparison of taxonomies reveal striking discrepancies among species delimitation methods in Madascincus lizards. PlosONE, 8, e68242. doi:10.1371/journal.pone.0068242

Miralles, A., Bruy, T., Wolcott, K., Scherz, M. D., Begerow, D., Beszteri, B., Bonkowski, M., Felden, J., Gemeinholzer, B., Glaw, F., Glöckner, F. O., Hawlitschek, O., Kostadinov, I., Nattkemper, T. W., Printzen, C., Renz, J., Rybalka, N., Stadler, M., Weibulat, T., Wilke, T., Renner, S., Vences, M. (2020). Repositories for taxonomic data: where we are and what is missing. Systematic Biology, 69, 1231-1253. doi:10.1093/sysbio/syaa026

Monaghan, M. T., Wild, R., Elliot, M., Fujisawa, T., Balke, M., Inward, D. J., Lees, D. C., Ranaivosolo R., Eggleton, P., Barraclough, T.G., \& Vogler, A.P. (2009). Accelerated species inventory on Madagascar using coalescent-based models of species delineation. Systematic Biology, 58, 298-311. doi:10.1093/sysbio/syp027

Padial, J.M., Miralles, A., De la Riva, I., \& Vences, M. (2010). The integrative future of taxonomy. Frontiers in Zoology, 7, 16. doi:10.1186/1742-9994-7-16

Pons, J., Barraclough, T. G., Gomez-Zurita, J., Cardoso, A., Duran, D. P., Hazell, S., Kamoun, S., Sumlin, W. D., \& Vogler, A. P. (2006). Sequence-based species delimitation for the DNA taxonomy of undescribed insects. Systematic Biology, 55, 595-609. doi:10.1080/10635150600852011

Postaire B., Magalon H., Bourmaud C. A., \& Bruggemann J. H. (2016). Molecular species delimitation methods and population genetics data reveal extensive lineage diversity and cryptic species in Aglaopheniidae (Hydrozoa). Molecular Phylogenetics and Evolution, 105, 36-49. doi:10.1016/j.ympev.2016.08.013

Puillandre, N., Lambert, A., Brouillet, S., \& Achaz, G. (2012b). ABGD, Automatic Barcode Gap Discovery for primary species delimitation, Molecular Ecology, 21, 1864-1877. doi:10.1111/j.1365-294X.2011.05239.x

Puillandre, N., Modica, M. C., Zhang, Y., Sirovich, L., Boisselier, M. C., Cruaud, C., Holford, M., Samadi, S. (2012a). Large-scale species delimitation method for hyperdiverse groups. Molecular Ecology, 11, 2671-3691. doi:10.1111/j.1365-294X.2012.05559.x

Puillandre, N., Brouillet, S., Achaz, G. (2021). ASAP: Assemble Species by Automatic Partitioning. Molecular Ecology Resources, 21(2), 609-620. doi:10.1111/1755-0998.13281

Rabiee, M., Mirarab, S. (2019). SODA: Multi-locus species delimitation using quartet frequencies. bioRxiv, 869396. doi:10.1101/869396

Rannala, B. (2015). The art and science of species delimitation. Current Zoology, 61, 846-853. doi:10.1093/czoolo/61.5.846

Ratnasingham, S., \& Hebert P.D.N. (2013). A DNA-based registry for all animal species: the Barcode Index Number (BIN) system. PLoS ONE, 8: e66213. doi:10.1371/journal.pone.0066213

Renner, M.A., Heslewood, M.M., Patzak, S.D., Schäfer-Verwimp, A., \& Heinrichs J. (2017). By how much do we underestimate species diversity of liverworts using morphological evidence? An example from Australasian Plagiochila (Plagiochilaceae: Jungermanniopsida). Molecular Phylogenetics and Evolution, 107, 576-593. doi:10.1016/j.ympev.2016.12.018

Samadi, S., \& Barberousse, A. (2006). The tree, the network, and the species. Biological Journal of the Linnean Society, 89(3), 509-521. doi:10.1111/j.1095-8312.2006.00689.x 
401

402

403

404

405

406

407

408

409

410

411

412

413

414

415

416

417

418

419

420

421

422

423

424

425

426

427

428

Sites, J. W., \& Marshall J. C. (2003). Delimiting species: a Renaissance issue in systematic biology. Trends in Ecology and Evolution, 18, 462-470. doi:10.1016/S01695347(03)00184-8

Sholihah, A., Delrieu-Trottin, E., Sukmono, T., Dahruddin, H., Risdawati, R., Elvira, R., Wibowo, A., Kusno, K., Busson, F., Sauri, S., Nurhaman, U., Zein, M. S. A., Fitriana, Y., Utama, I., Muchlisin, Z. A., Agnèse, J. F., Hanner, R., Wowor, D., Steinke, D., Keith, P., Rüber, L., Hubert, N., (2020). Disentangling the taxonomy of the subfamily Rasborinae (Cypriniformes, Danionidae) in Sundaland through DNA barcodes. Scientific Reports, 10 , 2818. doi:10.1038/s41598-020-59544-9

Solís-Lemus, C., Knowles, L.L., \& Ané, C. (2015). Bayesian species delimitation combining multiple genes and traits in a unified framework. Evolution, 69, 492-507. doi:10.1111/evo.12582

Spöri, Y., \& Flot, J. $\square$ F. (2020). HaplowebMaker and CoMa: two web tools to delimit species using haplowebs and conspecificity matrices. Methods in Ecology and Evolution, 11(11), 1434-1438. doi:10.1111/2041-210X.13454

Sukumaran, J., \& Knowles, L. (2017). Multispecies coalescent delimits structure, not species. Proceedings of the National Academy of Sciences USA, 114(7), 1607-1612. doi:10.1073/pnas.1607921114

Sukumaran, J., Holder, T. M., Knowles, L. L. (2020). Incorporating the speciation process into species delimitation. https://github.com/jeetsukumaran/delineate.

Vences, M. (2020). The promise of next-generation taxonomy. Megataxa, 1, 35-38. doi:10.11646/megataxa.1.1.6

Vences, M., Miralles, A., Brouillet, S., Ducasse, J., Fedosov, A., Kharchev, V., Kumari, S, Patmanidis, S., Puillandre, N., Scherz, M. D., Kostadinov, I., Renner, S. S. (submitted). iTaxoTools 0.1: Kickstarting a specimen-based software toolkit for taxonomists. Submitted manuscript will become publicly available on BioRxiv on 26 March 2021.

Vieites, D. R., Wollenberg, K. C., Andreone, F., Köhler, J., Glaw, F., \& Vences M. (2009). Vast underestimation of Madagascar's biodiversity evidenced by an integrative amphibian inventory. Proceedings of the National Academy of Sciences U. S. A., 106, 8267-8272. doi:10.1073/pnas.0810821106

Weisrock, D. W., Rasoloarison R. M., Fiorentino, I., Ralison, J. M., Goodman, S. M., Kappeler, P. M., \& Yoder, A.D. (2010). Delimiting species without nuclear monophyly in Madagascar's mouse lemurs. PLOS ONE, 5, e9883. doi:10.1371/journal.pone.0009883

Wiens, J. J., \& Penkrot, T. A. (2002). Delimiting species using DNA and morphological variation and discordant species limits in spiny lizards (Sceloporus). Systematic Biology, 51, 69-91. doi:10.1080/106351502753475880

Yang, Z., \& Rannala, B. (2010). Bayesian species delimitation using multilocus sequence data. Proceedings of the National Academy of Sciences U. S. A., 107, 9264-9269. doi:10.1073/pnas.0913022107

Yang, Z., \& Rannala, B. (2014). Unguided species delimitation using DNA sequence data from multiple loci. Molecular Biology and Evolution, 31, 3125-3135. doi:10.1093/molbev/msu279

Zhang, J., Kapli, P., Pavlidis, P., \& Stamatakis, A. (2013). A general species delimitation method with applications to phylogenetic placements. Bioinformatics, 29, 2869-2876. doi:10.1093/bioinformatics/btt499

Zhang, C., Zhang, D. X., Zhu, T., Yang, Z. (2011). Evaluation of Bayesian coalescent method of species delimitation. Systematic Biology, 60(6), 747-761. doi:10.1093/sysbio/syr071 


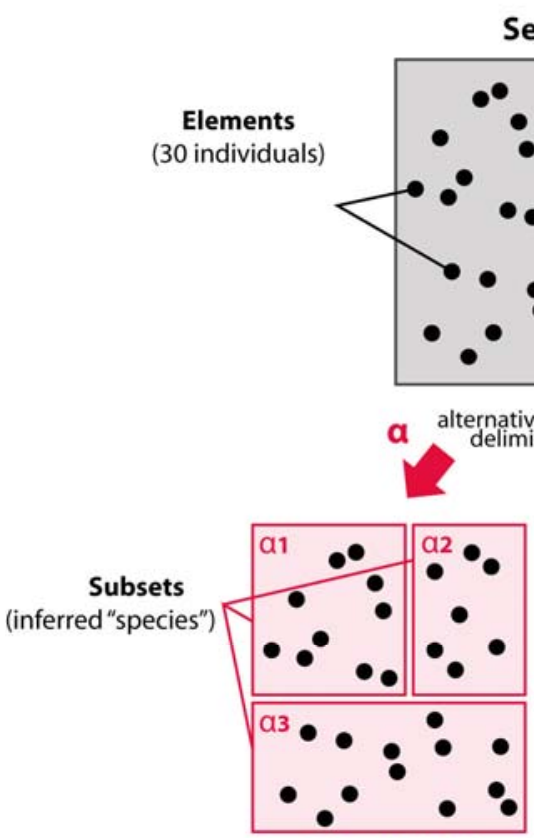

Partition a

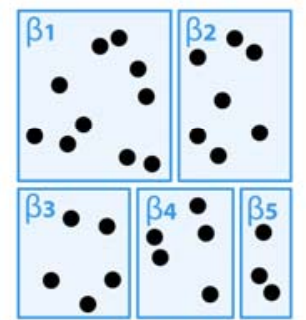

Partition $\beta$

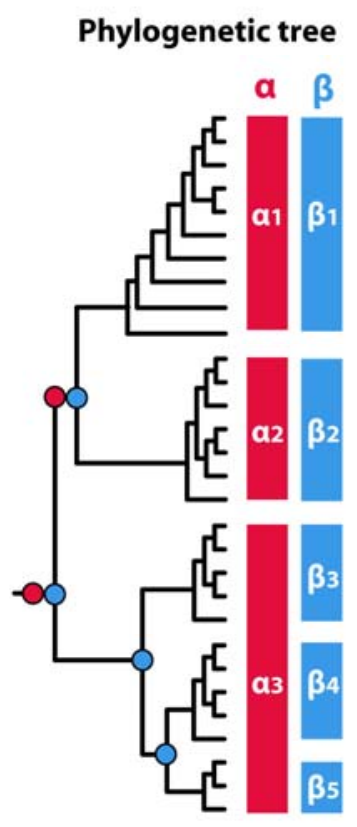

431

432

433

434

435

436

437

438

439

440

441

442

443

Figure 1. In mathematics, a partition of a set is a grouping of its elements into non-empty subsets, in such a way that every element is included in exactly one such subset. The main output of a species delimitation inference therefore corresponds to a partition, independently of the theoretical context, the biological input data, or the algorithms/models used. In our example, a set of 30 specimens is split by two different methods into two alternative partitions $\alpha$ and $\beta$, corresponding to 3 and 5 putative species (subsets), respectively. For the sake of clarity, these two alternative species partitions are represented as boxes reported next to each "species clade" in a phylogenetic tree, with hypothetical speciation events highlighted by circles via a corresponding color. Note that not all SD methods rely on a tree topology, and may therefore delimit non-monophyletic units (e.g., methods based on morphological or molecular divergence). 

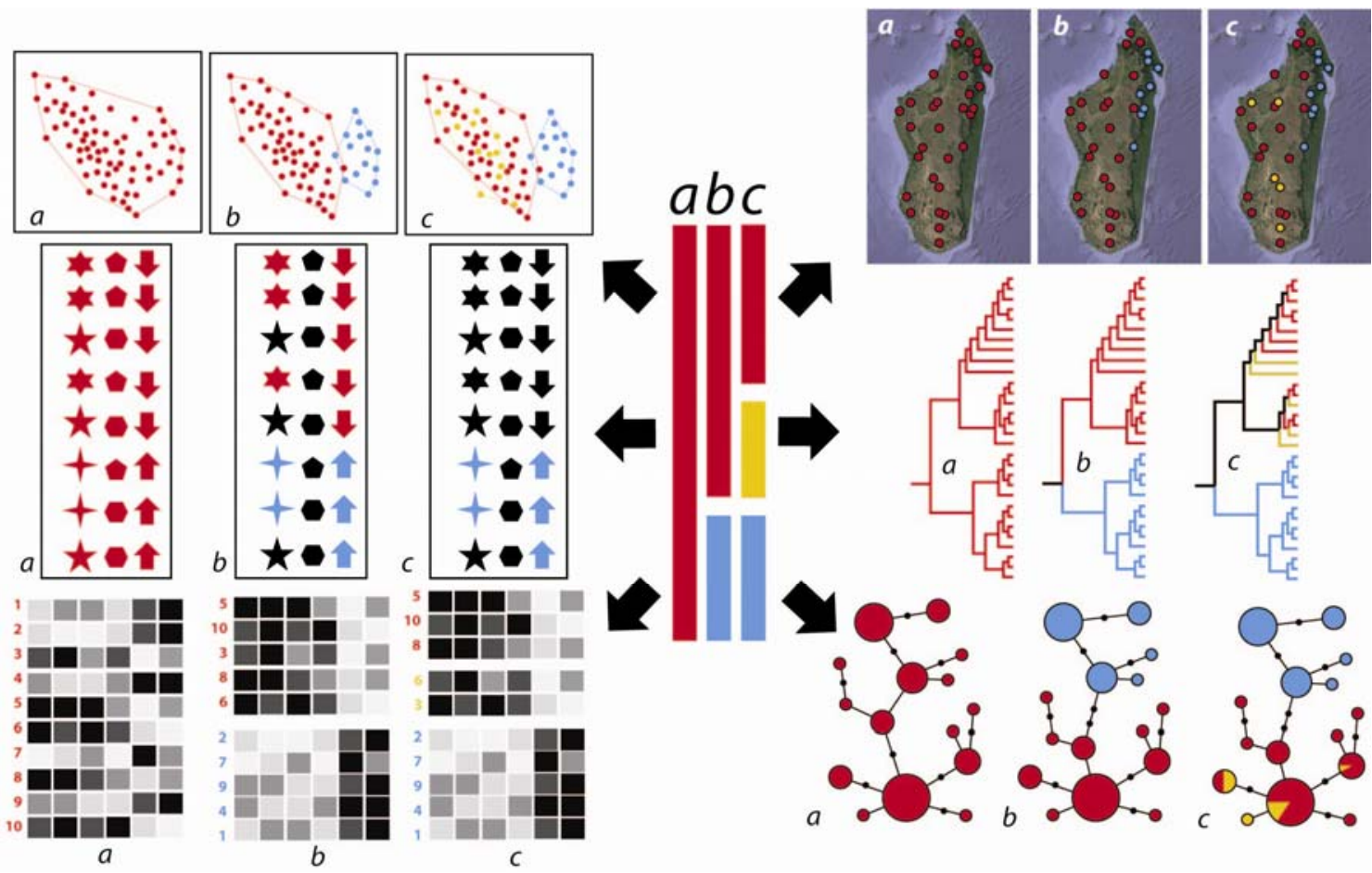

446

Figure 2. Illustration of exemplary potential applications of a species partition (SPART) file.

447 If it can be parsed by other programs, SPART might facilitate the exploration of taxonomic

448 datasets under various delimitation assumptions (such as morphometric Principal Component

449 Analysis, automated extraction of diagnostic traits, heatmap of meristic morphological traits,

450 distribution map, mitochondrial DNA-based phylogenetic tree, or haplotype network from

451 nuclear DNA). In the present example, the partition $b$ represents the optimal delimitation from

452 a taxonomic perspective. 
a)

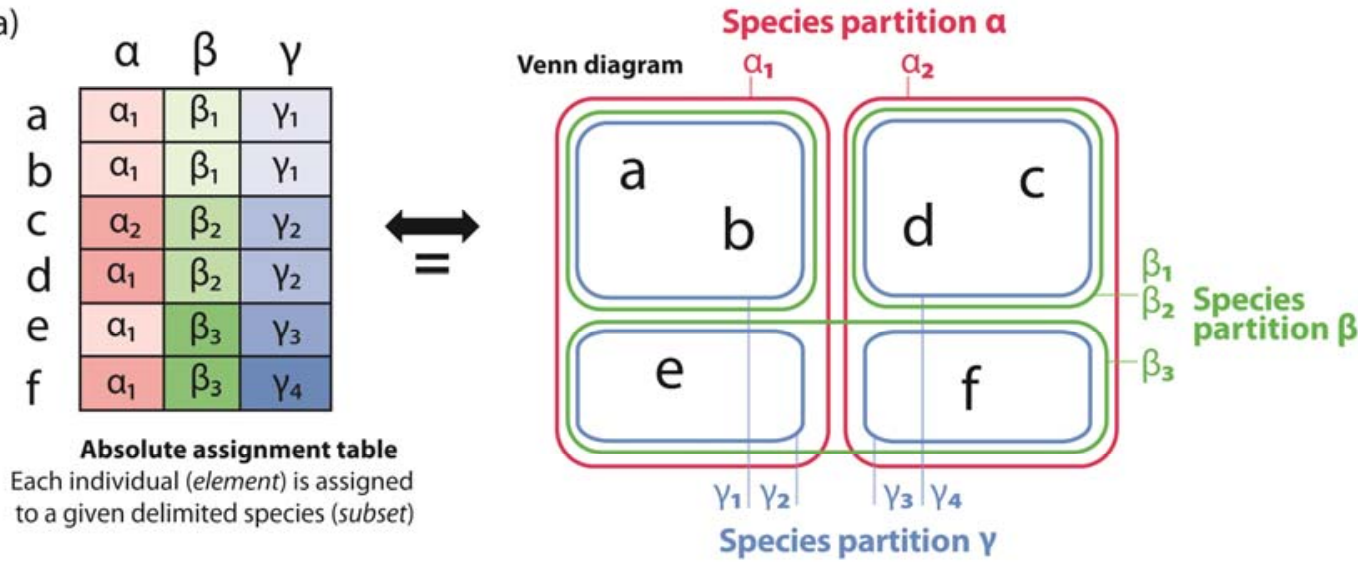

b)

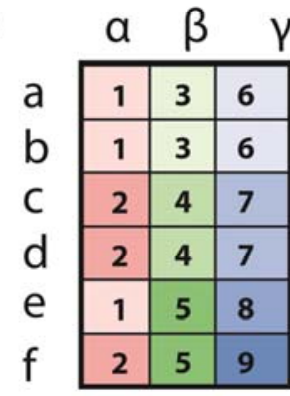

Absolute assignment table Each individual is assigned to a given species ID number, and each species of each partition has a unique ID number

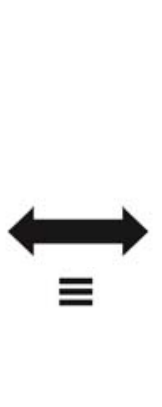

c)

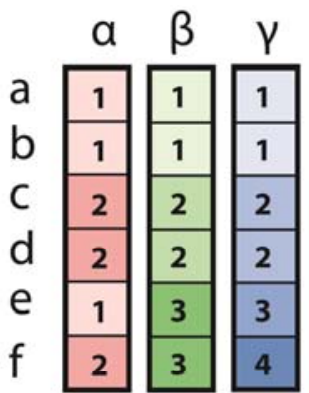

Relative assignment table Within the same species partition, each individual is assigned to a number indicating its belonging to a given subset. Numbers have no meaning per se out of a given species partition.
Figure 3. The SPART format can combine alternative species partitions of a same set of individuals (elements) into a unique multiple species partition file. (a) Example of set comprising six individuals split by three distinct SD analyses, resulting in three distinct species partitions $(\alpha, \beta$ and $\gamma)$. All these species partitions are hierarchically compatible (i.e. they conform to the mathematical definition of nested sets), with the exception of the pair $\alpha$ $\beta$ (Venn diagram representing the alternative species partitions on the right, and corresponding assignment table on the left). These alternative species partitions can be coded in SPART either (b) by using a unique numbering for all the three species partitions (so that each species partition has its own set of species (subset) numbers) or (c) by using one numbering system per species partition. The latter representation allows combining different species partitions into a multiple species partition file without having to adjust each species or cluster number (subset). Both (b) and (c) are fully equivalent in SPART format, because the coding of each partition is independent from the others (subset assignment numbers have no meaning per se, they only indicate, within each partition, the common assignment to a specific subset). 
472 Table 1. Automatedtools dedicated to species delimitation. Abbreviations used: mtDNA, mitochondrial DNA; nDNA, nuclear DNA. Note that

473 for programs marked with an asterisk (GMYC, PTP, SODA, DELINEATE) GUI-driven versions with SPART implementation have been

474 prepared in the context of the iTaxoTools project but SPART output is not yet provided by all available versions. Other programs (ABGD, 474 prepared in the context of the iTaxoTools project but
475 ASAP, TR2) already include native SPART output.

476

\begin{tabular}{|c|c|c|c|c|c|}
\hline Tools & General principle & $\begin{array}{c}\text { Hypothetical partition } \\
\text { needed as an input (a } \\
\text { priori species } \\
\text { assignement) }\end{array}$ & Optimal datasets and format & $\begin{array}{c}\text { SPART } \\
\text { impletementation }\end{array}$ & References \\
\hline $\begin{array}{l}\text { GMYC (mGMYC } \\
\text { and bGMYC) }\end{array}$ & $\begin{array}{l}\text { General mixed Yule- } \\
\text { coalescent model }\end{array}$ & No & mtDNA - ultrametric gene tree & Yes * & $\begin{array}{l}\text { Pons et al. (2006), Fontaneto et al. (2007), } \\
\text { Monaghan et al. (2009) }\end{array}$ \\
\hline BPP, iBPP & Multispecies coalescent model & $\begin{array}{l}\text { Both options are } \\
\text { possible }\end{array}$ & $\begin{array}{l}\text { nDNA - multilocus alignments }+ \\
\text { (optionally in iBPP) matrix of } \\
\text { morphological characters }\end{array}$ & In preparation & $\begin{array}{l}\text { Yang \& Rannala (2010, 2014), Solís- } \\
\text { Lemus et al. (2015) }\end{array}$ \\
\hline SPEDESTEM & $\begin{array}{l}\text { Maximum likelihood and } \\
\text { information theory }\end{array}$ & Yes & $\begin{array}{l}\text { nDNA - ultrametric gene trees from } \\
\text { multiple loci (nwk) }\end{array}$ & No & Ence and Carstens (2011) \\
\hline ABGD & DNA barcode gap detection & No & $\begin{array}{l}\text { mtDNA - sequence alignment or distance } \\
\text { matrix }\end{array}$ & Yes & Puillandre et al. (2012) \\
\hline $\begin{array}{l}\text { SPECIES } \\
\text { DELIMITATION }\end{array}$ & $\begin{array}{l}\text { Coalescence / tree based } \\
\text { approach }\end{array}$ & Yes & Topology (ultrametric tree) & No & Masters et al. (2011) \\
\hline BINs & $\begin{array}{l}\text { DNA barcode distance } \\
\text { threshold + Markov clustering. }\end{array}$ & No & mtDNA - sequence alignment & No & Ratnasingham \& Hebert (2013) \\
\hline $\begin{array}{l}\text { PTP (mPTP and } \\
\text { bPTP) }\end{array}$ & $\begin{array}{l}\text { Multi-rate Poisson ree } \\
\text { processes model }\end{array}$ & No & Non ultrametric tree (nwk or NEXUS tree) & $\begin{array}{l}\text { Yes (mPTP and } \\
\text { bPTP) * }\end{array}$ & $\begin{array}{l}\text { Zhang et al. (2013), } \\
\text { Kapli et al. (2016) }\end{array}$ \\
\hline DISSECT & Multispecies coalescent model & No & nDNA - multilocus alignments & No & Jones et al. (2014) \\
\hline TR2 & Multispecies coalescent model & No & $\begin{array}{l}\text { nDNA - rooted gene trees from multiple } \\
\text { loci (nwk) }\end{array}$ & Yes & Fujisawa et al. (2016) \\
\hline STACEY & Multispecies coalescent model & No & nDNA - multilocus alignments & No & Jones (2017) \\
\hline SODA & $\begin{array}{l}\text { Quartet frequencies, based on } \\
\text { coalescent model }\end{array}$ & No & Multiple gene tree topologies & Yes * & Rabiee \& Mirarab (2019) \\
\hline $\begin{array}{l}\text { HaplowebMaker / } \\
\text { CoMa }\end{array}$ & Mutual allelic exclusivity & No & nDNA - multilocus alignments & No & Spöri \& Flot (2020) \\
\hline ASAP & $\begin{array}{l}\text { Distance-based partitions + } \\
\text { coalescent-based scoring }\end{array}$ & No & $\begin{array}{l}\text { mtDNA - sequence alignment or distance } \\
\text { matrix }\end{array}$ & Yes & Puillandre et al. (2021) \\
\hline DELINEATE & Multispecies coalescent model & Yes & Rooted ultrametric tree (nwk or NEXUS) & Yes * & Sukumaran et al. (2020) \\
\hline
\end{tabular}




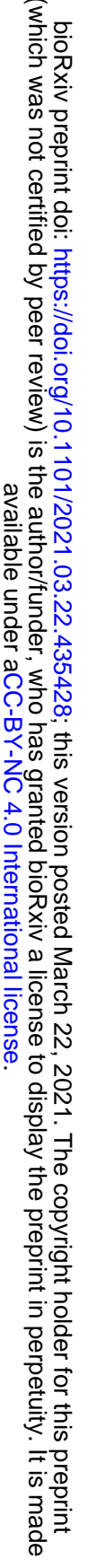

